\title{
Ecological interactions and habitat modification in nesting Common Murres, Uria aalge
}

\author{
JULIA K. PARRISH and ROBERT T. PAINE
}

\begin{abstract}
Summary
Seabird populations suffer from a variety of natural and human-induced sources of mortality and loss of lifetime reproductive output. On the outer coast of Washington State, Common Murre Uria aalge populations have been in decline for approximately the last decade and are currently reproductively active only at Tatoosh Island. These murres nest in two basic habitat types: crevices (25\% of the population) and larger cliff-top subcolonies $(75 \%)$. Murres in cliff-top subcolonies have suffered dramatic reductions in reproductive success in recent years relative to conspecifics nesting in the crevices, primarily due to egg predation by Glaucous-winged Gulls Larus glaucescens and Northwestern Crows Corvus caurinus, facilitated by the presence of Bald Eagles Haliaeetus leucocephalus. Because predator removal is not feasible and creation of additional crevice habitat is difficult, expensive and potentially ineffective, we have designed a temporary habitat modification (the "silk forest") which replaces the natural vegetation cover and modifies the interaction between murres and eagles. Within the test subcolony, murres nesting under and immediately adjacent to the silk forest produced nearly twice as many eggs per square metre as their conspecifics nesting in adjacent exposed-ground areas.
\end{abstract}

\section{Introduction}

Seabird species in the North Pacific have been affected by a number of direct and indirect human-induced effects (e.g. hunting, egg collection, introduced predators, pollution, fishing, and habitat alteration/loss; see examples in Nettleship et al. 1984 and Vermeer et al. 1993). In restoring wild populations damaged by human-induced disturbance, conservation biologists and wildlife managers often attempt to augment the remaining population, either actively or passively (Temple 1977a). Active approaches involve the addition or removal of organisms by humans (e.g. stock supplementation, captive breeding), or the removal of a competitor or predator species (Kress 1983, Kress and Nettleship 1988). Passive intervention includes methods in which organisms are not directly handled but the environment necessary for species survival is altered and usually takes the form of habitat restoration or even creation (e.g. the provision of nesting sites). Both types of intervention seek to increase the adult population and/or the breeding success of that population.

Temple (1977b) suggested that manipulation of inherent behavioural patterns, or traditions, might be a useful management tool for increasing endangered bird populations in situations where economic and/or social conflicts prevented 
a more proactive approach. Kress (1983), in an attempt to restore locally extirpated stocks of Common Terns Sternus hirundo, pioneered this approach by utilizing social signals, dummies and playbacks to attract prospective breeders by exploiting a basic aspect of the biology of the birds - gregarious nesting - to facilitate population restoration. Here we propose a procedure for restoration of colonial nesting seabirds which combines habitat modification with inherent seabird social tendencies as well as a recognition of established community interactions.

\section{Site and methods}

Common Murres Uria aalge are highly gregarious, holarctic seabirds (Tuck 1961). Although they are globally abundant (approximately 1.3 million birds along the west coast of North America, exclusive of the Bering Sea; Byrd et al. 1993), they have become locally depauperate due to several, often compounded, effects. On the coast of Washington State, murre numbers have been reduced by oil spill mortalities (Burger and Fry 1993), the El Niño-Southern Oscillation of 198283 (Wilson 1991) and an unknown impact of gill-net fishing (DeGange et al. 1993). At present, murres breed annually at a single location, Tatoosh Island, in the north-west corner of the state (U. Wilson pers. comm.). Tatoosh Island $\left(48^{\circ} 24^{\prime} \mathrm{N}, 124^{\circ} 44^{\prime} \mathrm{W}\right)$ is a complex of flat-topped, rocky islets, the largest of which are predominantly covered by a dense, 1-2 $\mathrm{m}$ high stand of salmonberry Rubus spectabilis.

The Tatoosh population seems to be unique in Washington in that it experienced a dramatic rise in population size over the same time period that

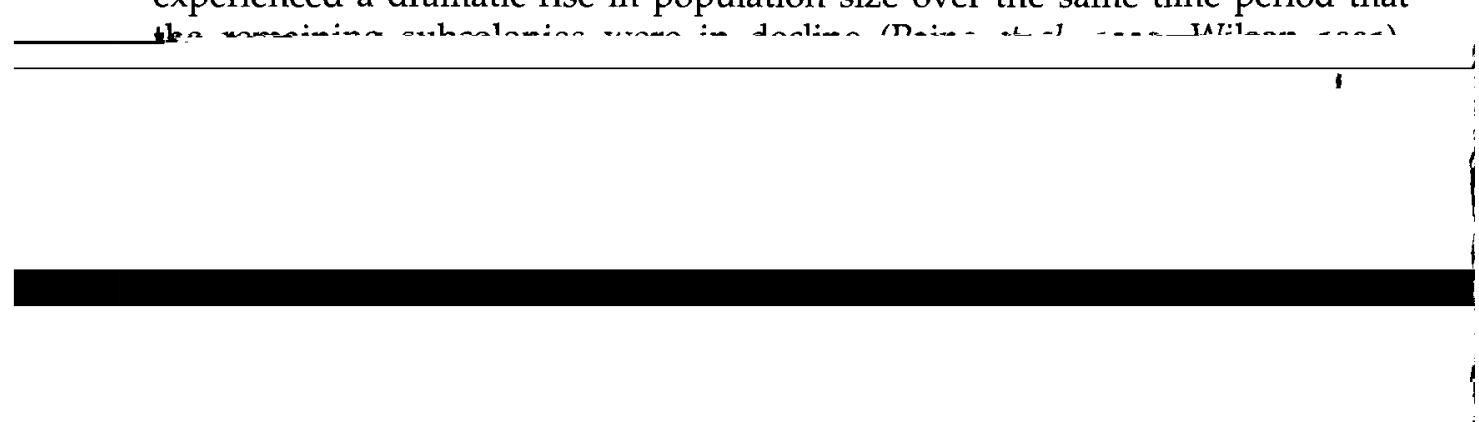

Murres on Tatoosh breed in two types of habitat: natural crevices in vertical cliff walls and open space on the cliff-top, adjacent to and underneath the salmonberry cover. Subcolonies are defined as a group of murres separated from adjacent groups by physical barriers (e.g. cliff-face, unused vegetative cover). Cliff-top subcolonies, unlike crevice subcolonies, are not space-limited and, as such, are much larger than even the largest crevice subcolony and host the majority (approximately $75 \%$ ) of the current Tatoosh murre population (5,000-6,000 birds). Incidental photographs prior to 1980 indicate that the crevice subcolonies were completely colonized at that time and suggest that the main cliff-top (MCT) subcolony was not yet in existence (R. T. Paine unpubl. data; Figure 1). Thus, the growth of the Tatoosh population during the 1980 os occurred

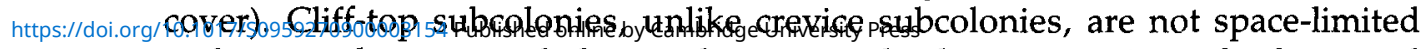


over-fertilization (Paine et al. 1990). Direct measurements of the areal extent of bare ground, started in 1988 and made during the non-breeding season, indicate that the murres are altering the habitat at a rate of approximately $26 \mathrm{~m}^{2}$ per year (Figure 2).

The rapid expansion of the cliff-top subcolonies, concomitant with the salmonberry die-back, have left the majority of the Tatoosh murre population in reduced quality nesting habitat because murres nesting in the exposed cliff-top areas are subject to disturbance during visits to the Island by Bald Eagles Haliaeetus leucocephalus. Eagles are frequently observed on Tatoosh during the murre nesting season and the local population is increasing (Parrish 1995, J. K. Parrish and R. T. Paine, unpublished data). Regardless of whether eagles attack the murres or merely fly by them, murres on cliff-top subcolonies respond by temporarily vacating the subcolony for the safety of the water. Subcolonies remain vacant from minutes to hours, allowing egg predators Glaucous-winged Gulls Larus glaucescens, and Northwestern Crows Corvus caurinus - unimpeded access to eggs (Parrish 1995). This pattern of repeated disturbance has caused the reproductive failure of the MCT in four of the last six years (J. K. Parrish unpublished data).

Because the majority of Tatoosh murres nest on the cliff-top, continued failure of these subcolonies will cause a crash in population size in the absence of continued immigration. Traditional manipulations used to restore declining populations are not appropriate in this context. As a threatened species in Washington State, and the national bird of the U.S.A., removal of Bald Eagles is not feasible. At present, nesting gulls number in the thousands and crows are abundant (c. 15 pairs on Tatoosh and hundreds more on the mainland 0.6 $\mathrm{km}$ distant), making their sustained removal difficult as well. The use of social facilitation is also not appropriate as the Island is already colonized and there is indirect evidence that prospecting murres naturally recruit to the now low quality areas (see Figure 1). Finally, it is not clear that extreme measures such as captive breeding or creation of high quality habitat (e.g. crevices) are warranted or feasible.

High-quality habitat can be defined as providing the murres with: (1) enough secure space to lay eggs and raise chicks, as well as (2) relative security to the adults from raptor attack. Initially, the cliff-top subcolonies met this definition. However, at present they only provide the former because the salmonberry die-back has substantially degraded the latter. Our habitat modification procedure is designed to artificially recreate prime habitat, thus reversing a cycle of habitat degradation associated with murre occupancy (Figures 1 and 2).

Prior to the onset of the murre breeding season (April) two $3.25 \mathrm{~m}^{2}$ grids of silk-enhanced artificial "trees" (silk forests), were placed on the MCT abutting the live salmonberry cover and separated from each other by $2.6 \mathrm{~m}$ of bare ground within a part of the MCT that had been used by nesting pairs in previous years (Figure 3). Each tree was constructed from a $90 \mathrm{~cm}$ stake, driven into the ground to a final height of $75 \mathrm{~cm}$ (adjacent live salmonberry leaves started at approximately $60 \mathrm{~cm}$.). Stakes were uniformly arrayed at $40 \mathrm{~cm}$ intervals. A set of artificial branches were affixed to each stake with tie-wraps (Figure 3). Leaves extended $5 \mathrm{~cm}$ above the stake in a $25 \mathrm{~cm}$ radius, providing almost total cover analogous to that provided by the live salmonberry. Unlike structural habitat 
a

b
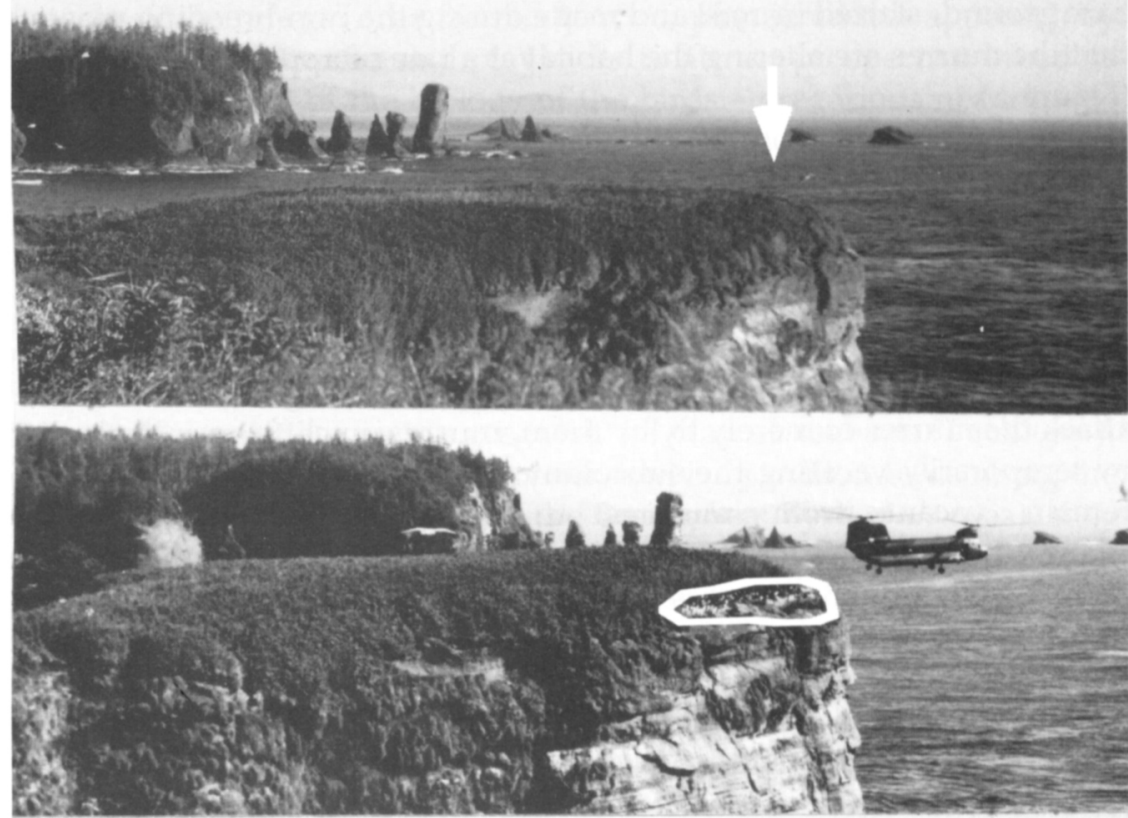

C

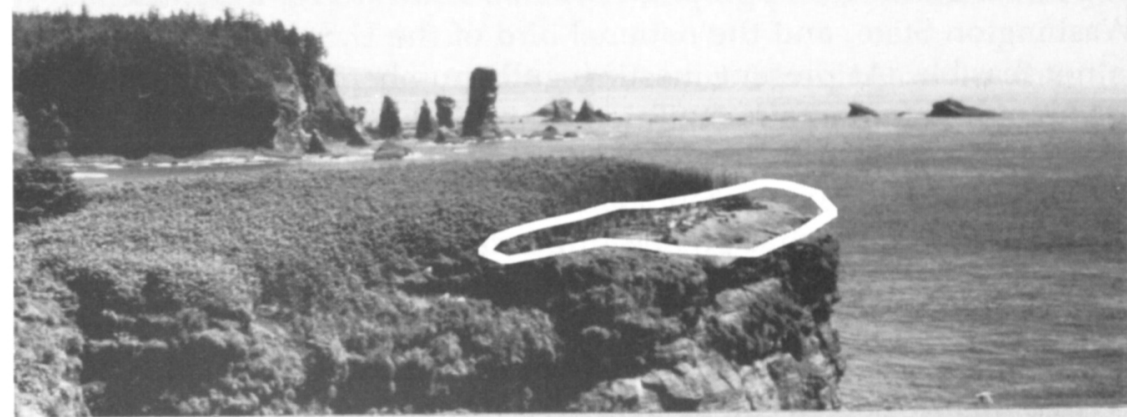

d

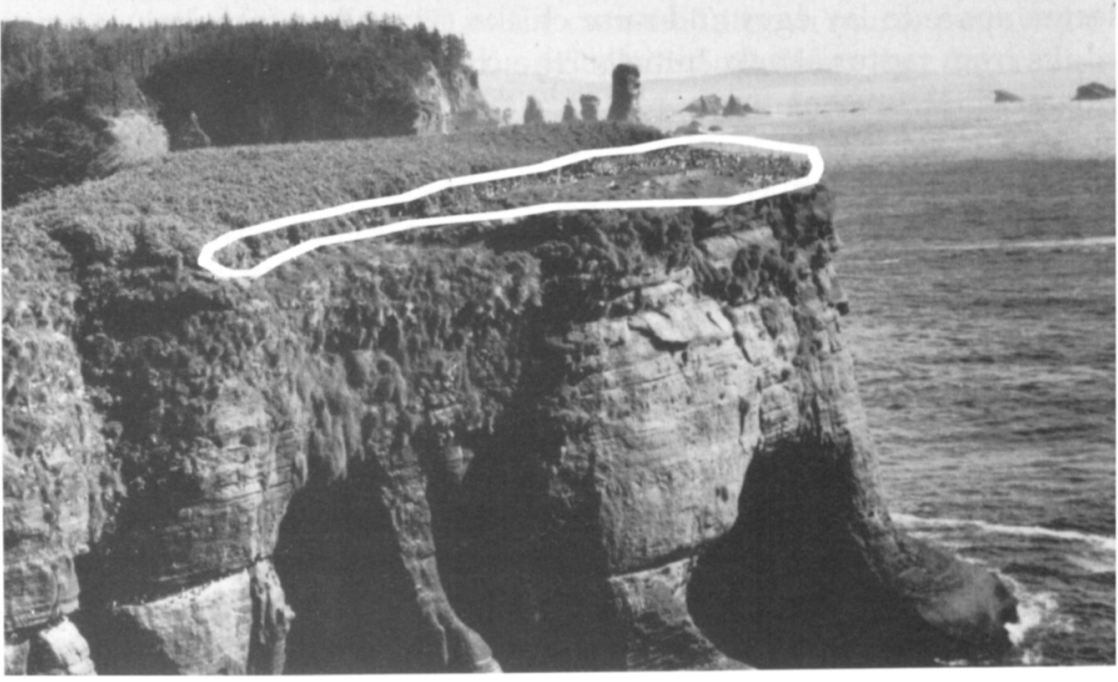




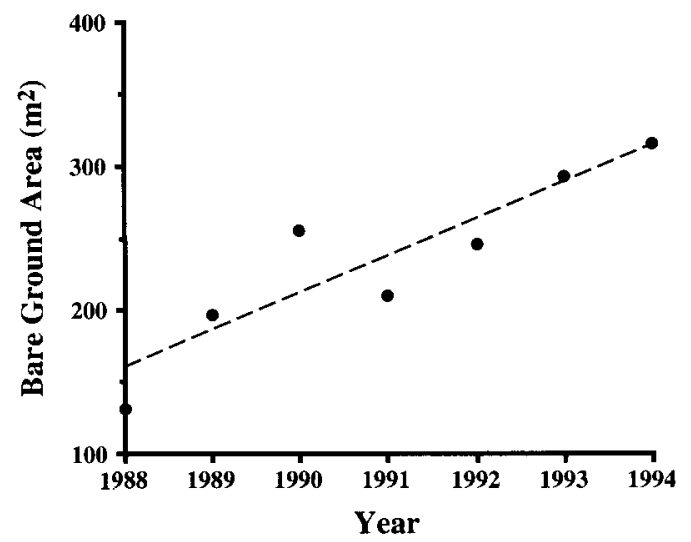

Figure 2. Areal coverage of bare ground progressively exposed on the MCT (see Figure 1). A simple linear regression indicates that salmonberry is dying back at a rate of approximately $26 \mathrm{~m}^{2}$ per year.

changes, but comparable to passerine nesting boxes, the silk forests are temporary installations, completely removable at the end of the breeding season.

Reproductive output, murre presence on the subcolony, and murre-eagle interactions were assessed from a promontory approximately $150 \mathrm{~m}$ away from the MCT. Previous work has indicated that researcher presence at this viewing station did not adversely affect the behaviour of the murres (J. K. Parrish, unpubl. data). All data were collected after laying had begun, on 17-26 June and 8-11 July 1994 (after when egg laying ceased). The number of eggs were counted during approximately $50 \mathrm{~h}$ of observation as well as three visits to the MCT during temporary abandonment by the murres. Eggs were individually identified by date of laying, location, colour and fate. Because we were not present over the entire laying season and did not continuously observe on those days we were present, egg totals represent a conservative total. Production data are presented for the modified area (i.e. north and south silk forests and the area in between, $11.2 \mathrm{~m}^{2}, 24 \%$ of total nesting area) and control area (i.e. bare ground area immediately south, $\left.18.8 \mathrm{~m}^{2}, 40 \%\right)$. Unfortunately, eggs laid under the live salmonberry (approximately $17.0 \mathrm{~m}^{2}$ ) were not adequately visible to count accurately. However, in previous years, egg production in the salmonberry was higher than in the bare ground area (Parrish 1995).

\section{Results and discussion}

Murres colonized all available space on the MCT, indicating that they are readily able to incorporate artificially covered nesting areas into their habitat repertoire.

Figure 1. A photographic sequence of the birth and expansion of the largest cliff-top subcolony of Common Murres (MCT) on Tatoosh Island. a, 7 June 1970; b, 10 July 1987; c, 6 August 1990; d, 9 May 1994. Cliff height (see photograph D) is approximately $35 \mathrm{~m}$. Note the progressive exposure of bare ground (i.e. the majority of the nesting area) as the salmonberry cover recedes from the cliff edge (outlined). Both the 1987 and the 1994 photograph show murres on the MCT. 


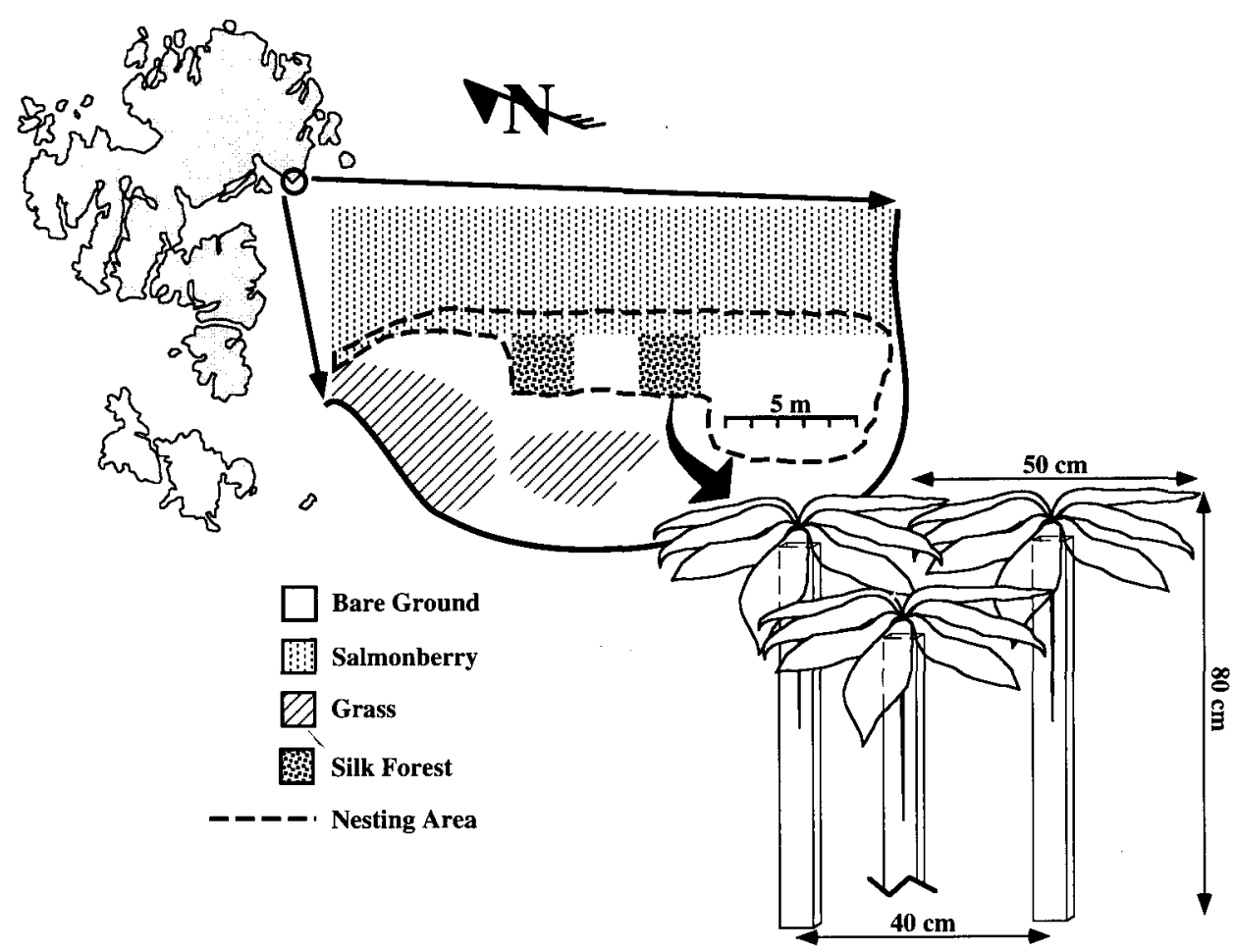

Figure 3. Diagrammatic representation of the silk forest habitat manipulation. The MCT is located at cliff's edge on the south-west tip of the main island. During 1994, murres nested within the dashed line: under live salmonberry, in and in between the silk forests, and in the adjacent exposed area. No murres nested in the grass, or on the eroded sections of bare ground along the cliff perimeter.

Density in all areas (modified, control and native salmonberry) appeared to be equal and maximal, that is, the birds nested shoulder to shoulder.

Over the 14 days of observation, egg production (eggs $/ \mathrm{m}^{2}$ ) in the modified area (124 eggs, $11.1 \mathrm{eggs} / \mathrm{m}^{2}$ ) was approximately twice that in the control area (108 eggs, $5.8 \mathrm{eggs} / \mathrm{m}^{2}$ ). New eggs appeared in both areas on all surveyed days, thus this difference is not due to subtleties of phenology across the subcolony. Whether this difference was due to a higher rate of predation in the flat (i.e. egg retention differences), higher fecundity in the modified habitat, and/or movement of breeders from the flat into the modified habitat is uncertain.

In addition to higher production, murres nesting in the modified area spent more time on the subcolony than did their conspecifics nesting on the control area. During our observations, eagle overflights caused some percentage of murres nesting on the MCT to flush on 19 occasions. Data were collected by mapping the remaining murres, relative to area type, immediately after murres ceased evacuating (1-3 minutes). Situations in which the subcolony had been at $100 \%$ present prior to eagle overflight were considered independent of each other $(n=13)$. Murres which left considered the eagle a threat dire enough to abandon their nesting site and/or egg. Remaining murres apparently perceived their risk as relatively lower. Because all murres were in the same phenological 


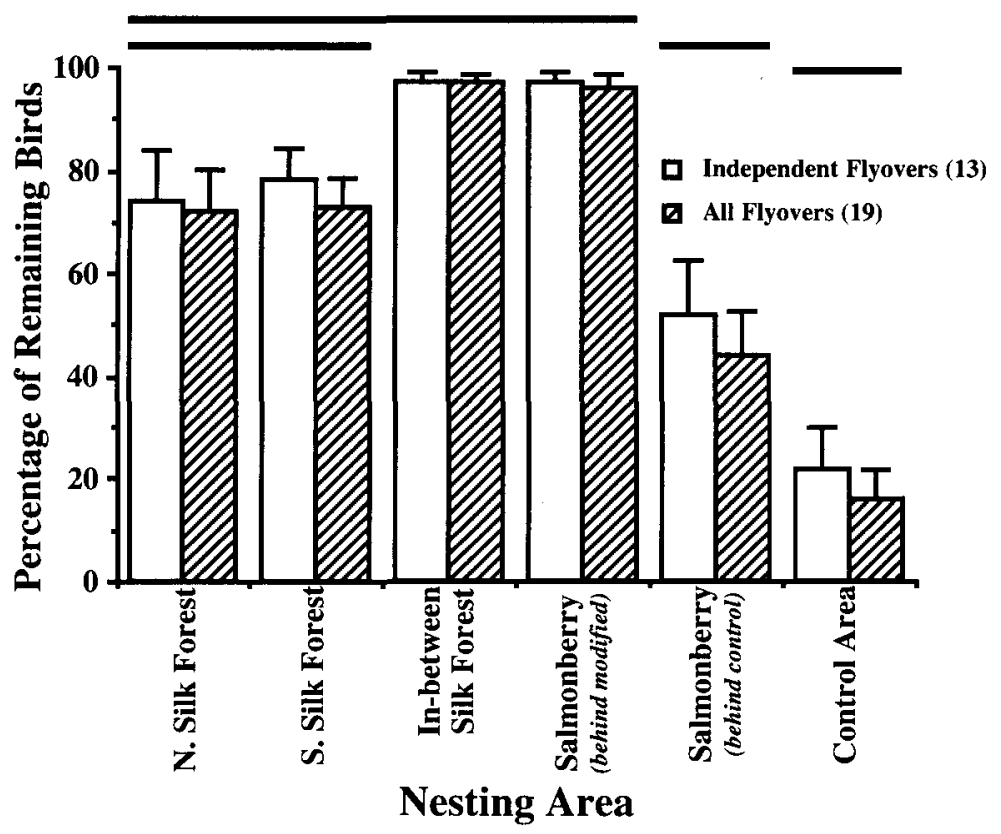

Figure 4. The percentage of nesting murres remaining on the MCT, by habitat type, immediately after an eagle has flown over the subcolony causing some percentage of the birds to evacuate their nests for the water (mean and standard error). Open bars are occasions in which the subcolony had been completely full (i.e. $100 \%$ attendance in all habitat types) prior to eagle flyover. Hatched bars include sequential flyovers by eagles, causing progressive evacuation by the murres. Lines above the graph indicate statistically significant differences in murre "staying power" (Tukey multiple range test on arcsine square root transformed percentages).

stage, spatial patterns associated with remaining murres may indicate how habitat functions to mediate risk perception.

Nearly all murres nesting in the salmonberry behind the silk forests, in between the silk forests, or in the silk forests themselves remained after eagle disturbance (Figure 4). By contrast, significantly more of the murres nesting in the control area left the subcolony (Tukey multiple range test on arcsine square root transformed percentages, flat versus all other areas; $P<0.001$ for all comparisons except salmonberry-behind-control for which $P=0.029$; Figure 4 ). Murres nesting in adjacent crevice subcolonies never left during eagle flyovers $(n=19)$. However, during the 1994 season, the MCT failed to produce chicks, even in the modified area. We believe this is due to the fact that silk forests, although effective, covered only a minor portion of the total MCT nesting area. In the face of repeated eagle flyovers, declining subcolony attendance, and delay in resettlement by evacuees, murres nesting in the manipulated area ultimately succumbed to the perceived danger presented by eagle presence and evacuated themselves, leaving their eggs to waiting gulls and crows. However, increasing the area of silk forest cover may tip the balance in favour of successful reproduction. We intend to test this proposition during the 1996 murre breeding season. 


\section{Conclusions}

Adult murres suffer from a variety of human-induced sources of mortality. Although seabird conservation should include proactive approaches to solving these problems, any attempt at population restoration needs to address community-specific interactions which may exacerbate the problem as well as the economic and social realities of large-scale long-term conservation strategies. On Tatoosh, Bald Eagles represent more of a perceived than actual threat; however, their effect on murre reproductive success and thus population demography over the long term is very real (Parrish 1995).

Minimal (and reversible) habitat modification appears to provide an effective means of enhancing murre reproductive output. Our silk forest technique provides physical protection to the murres and mediates their perception of eagle risk. Both elements should contribute to enhanced reproductive output. Our technique is especially appealing because it is environmentally benign and, when applied on a larger spatial scale, promises to be effective not only in increasing egg density but also in the production of viable chicks. We believe such defensive measures will be increasingly necessary as effective conservation/restoration programmes augment the regional presence of predators. Successfully altering the relationship between eagles, egg predators, and murres, to the benefit of the murres, may buy the population enough time for more long-term conservation measures requiring a change in human behaviour to take effect.

\section{Acknowledgments}

The authors wish to thank the Makah Indian Nation and the U.S. Coast Guard for continued access to Tatoosh Island. D. Stouder, J. Ruesink and T. Wootton provided needed field assistance. Comments by J. Wingfield and T. Gaston improved the manuscript. This research was made possible by a U.S. Fish and Wildlife grant to J.K.P. and NSF grant OCE-91-15760 to R.T.P. U.W. Raptor Research Center contribution \#6.

\section{References}

Burger, A. E. and Fry, D. M. (1993) Effects of oil pollution on seabirds in the northeast Pacific. Pp. 254-263 in K. Vermeer, K. T. Briggs, K. H. Morgan and D. Siegel-Causey eds. The status, ecology and conservation of marine birds of the North Pacific. Ottawa: Canadian Wildlife Service (Special Publ.).

Byrd, G. V., Murphy, E. C., Kaiser, G. W., Kondratyev, A. Y. and Shibaev, Y. V. (1993) Status and ecology of offshore fish-feeding alcids (murres and puffins) in the North Pacific. Pp. 176-186 in K. Vermeer, K. T. Briggs, K. H. Morgan, and D. Siegel-Causey eds. The status, ecology and conservation of marine birds of the North Pacific. Ottawa: Canadian Wildlife Service (Special Publ.).

DeGange, A. R., Day, R. H., Takekawa, J. E. and Mendenhall, V. M. (1993) Losses of seabirds in gill nets in the North Pacific. Pp. 204-211 in K. Vermeer, K. T. Briggs, K. $\mathrm{H}$. Morgan, and D. Siegel-Causey eds. The status, ecology and conservation of marine birds of the North Pacific. Ottawa: Canadian Wildlife Service (Special Publ.). 
Kress, S.W. (1983) The use of decoys, sound recordings, and gull control for re-establishing a tern colony in Maine. Col.Waterbirds 6: 185-196.

Kress, S.W. and Nettleship, D. N. (1988) Re-establishment of Atlantic Puffins (Fratercula arctica) at a former breeding site in the Gulf of Maine. J. Field Orn. 59(2): 161-170.

Nettleship, D. N., Sanger, G. A. and Springer, P. F. (1984) Marine birds: their feeding ecology and commercial fisheries relationships. Ottawa: Canadian Wildlife Service (Special Publ.).

Paine, R. T., Wootton, J. T. and Boersma, P. D. (1990) Direct and indirect effects of Peregrine Falcon predation on seabird abundance. Auk 107: 1-9.

Parrish, J. K. (1995) The influence of group size and habitat type on reproductive success in Common Murres (Uria aalge). Auk 112(2): 390-401.

Temple, S. A. (1977a) The concept of managing endangered birds. Pp. 3-7 in S. A. Temple, ed. Endangered birds: management techniques for preserving threatened species, Madison: University of Wisconsin Press.

Temple, S. A. (1977b) Manipulating behavioral patterns of endangered birds: A potential management technique. Pp. $435-443$ in S. A. Temple, ed. Endangered birds: management techniques for preserving threatened species, Madison: University of Wisconsin Press.

Tuck, L. M. (1961) The murres: their distribution, populations and biology. Ottawa: Canadian Wildlife Service (Monogr. 1).

Vermeer, K., Briggs, K. T., Morgan, K. H. and Siegel-Causey, D. (1993) The status, ecology, and conservation of marine birds of the North Pacific. Ottawa: Canadian Wildlife Service (Special Publ.).

Wilson, U. W. (1991) Responses of three seabird species to El Niño events and other warm water episodes on the Washington Coast, 1979-1990. Condor 93: 853-858.

JULIA K. PARRISH, ROBERT T. PAINE

Department of Zoology, University of Washington, Box 351800, Seattle, WA 98195, USA 